\title{
COLONIALIDAD Y DES/COLONIALIDAD EN AMÉRICA LATINA: ELEMENTOS TEÓRICOS
}

\author{
JULIO MEJÍA NAVARRETE* \\ Universidad Nacional Mayor de San Marcos \\ Lima, Peru
}

La originalidad de la propuesta de la des/colonialidad del poder se relaciona con la elaboración de una teoría para comprender América Latina como parte constitutiva de la modernidad. La des/colonialidad del poder ante todo significa el desarrollo de una teoría que explique la modernidad y delinee una posible alternativa. Cualquier opción de des/colonialidad estima como condición indispensable una des/colonialidad de la teoría social.

La colonialidad del poder es una teoría de la sociedad moderna y los procesos que llevaron a su desarrollo. Después de muchos años tenemos una propuesta teórica integral sobre la modernidad elaborada desde América, a partir de los márgenes del pensamiento europeo hegemónico, del liberalismo y el marxismo. Teoría que marca un hito central en la descripción de la sociedad contemporánea, que no pretende ser la única, solamente traza un planteamiento que aspira a ser un punto de partida abierto para el debate y la investigación. Sin embargo, la teoría posibilita más que comprender la realidad moderna, también establece la oportunidad de explicar y anticipar los fenómenos, con lo cual proporcionan lineamientos para la crítica y la acción futura.

Teoría que hunde sus raíces en la originalidad y la audacia de las propuestas de Aníbal Quijano1, pensamiento que expresa el encuentro creativo de la rica tradición cognoscitiva de América Latina que se remonta a Guaman Poma de Ayala, José Carlos Mariátegui, la teoría de la dependencia, la teología de la liberación del Padre Gustavo Gutiérrez, y, a

\footnotetext{
* Professor da Universidad Nacional Mayor de San Marcos e da Universidad Ricardo Palma, Lima, Peru.

${ }^{1}$ Aníbal Quijano: “Colonialidad y modernidad/racionalidad”. En Perú Indígena, vol. 13, $\mathrm{N}^{\circ} 29$, Instituto Indigenista, Lima 1992. Trabajo que da inicio a un movimiento de raíces andinas, ahora claramente proyectado a nivel mundial.
} 
la vez, de los desarrollos del pensamiento social global contemporáneo, expresados en la obra de Wallerstein. Aunque, es importante subrayar que su desarrollo se lleva a cabo en debate con diversos autores que han ido confluyendo en un proyecto colectivo, cabe destacar los aportes de Arturo Escobar, Walter Mignolo, Edgardo Lander, Catherine Walsh, Rita Laura Segato, Agustín Lao-Montes, Santiago Castro Gómez, Nelson Maldonado Torres, entre otros.

Lo central de la propuesta teórica consiste en mostrar que América Latina, si bien tiene que estudiarse desde la perspectiva de la dependencia europea, la comprensión cabal pasa necesariamente por su conformación en la propia modernidad. Donde modernidad y colonialidad son dimensiones interrelacionadas de una misma realidad. El debate teórico permite situar a América en el horizonte de la colonialidad y, a la vez, proyectarla más allá de los límites definidos por la modernidad. Por otro lado, la propuesta teórica desarrolla una estrategia interpretativa que consiste en develar los cimientos teóricos eurocéntricos, de superar aquella forma de comprender la realidad de América según categorías que fueron elaboradas para dar cuenta el mundo europeo, concepción que se transformó en una visión de alcance y validez universal.

En este trabajo se aborda la propuesta sobre la des/colonialidad de América Latina y la sociedad contemporánea, a partir de los desarrollos teóricos elaborados por Aníbal Quijano. Este artículo no espera ser exhaustivo, lo que interesa es destacar para el debate la emergencia, por una parte, de una teoría general de la existencia social y el poder, por otra parte, subrayar la elaboración de una teoría más concreta sobre la modernidad/colonialidad/eurocentrada, con la consiguiente crisis sistémica del mundo moderno global. También, se expone a partir de la teoría las cuestiones fundamentales que pueden llevar a delinear los caminos posibles de una alternativa societal.

\section{Existencia social y teoría del poder}

La teoría sobre la existencia social y el poder permite desarrollar una comprensión de carácter general sobre la organización de la sociedad y el comportamiento social. Propuesta desarrollada por Aníbal Quijano como el 
patrón de poder de la existencia social ${ }^{2}$, que ha posibilitado a las ciencias sociales, de modo particular en América Latina, superar la parálisis cognoscitiva y la hegemonía del eurocentrismo ${ }^{3}$.

La existencia social es un conjunto interrelacionado de ámbitos vitales de sobrevivencia y reproducción de la especie humana, es la forma en que los individuos, grupos e instituciones se estructuran socialmente. La organización de la existencia social sólo es posible por la presencia de los siguientes ámbitos interconectados ${ }^{4}$ :

1) El sexo, sus recursos y productos. La reproducción de la especie humana es posible cuando se establece un intercambio de comportamientos sociales entre hombre y mujer.

2) El trabajo, sus recursos y sus productos. Es la actividad productiva que se realiza para la sobrevivencia humana.

3) La subjetividad, sus recursos y productos. Las relaciones sociales son intercambios de comportamientos objetivos y de significados compartidos, son dimensiones de una misma realidad social.

4) La autoridad colectiva, sus recursos y sus productos. Es la instancia global de articulación entre los diferentes ámbitos y la organización societal.

2 Aníbal Quijano: "Colonialidad del poder, sexo y sexualidad", en Carmen Pimentel (org.): Poder, ciudadania, derechos humanos y salud mental en el Perú", CECOSAM, Lima, 2009c. También su trabajo "Poder y derechos humanos", en Carmen Pimentel (ed.): Poder, salud mental y derechos humanos", CECOSAM, Lima, 2001. "Colonialidad del poder y clasificación social", en Journal of World Systems Reseach, Volume XI, ${ }^{\circ}$ 2, Colorado, USA, 2000. Artículos donde los cinco ámbitos de la existencia social aparecen explícitamente formulados.

${ }^{3}$ Una discusión más amplia sobre el desarrollo de las ciencias sociales y el eurocentrismo puede encontrarse en Julio Mejía Navarrete: Sociedad y conocimiento. Los desafíos de la sociología latinoamericana, Fondo Editorial de la Facultad de Ciencias Sociales, Universidad Nacional Mayor de San Marcos, Lima, 2009.

${ }^{4}$ Aníbal Quijano considera que los ámbitos básicos de la existencia social capaces de reproducirse en el tiempo, son dimensiones abiertas dependiendo de las necesidades vitales de la complejidad de la sociedad. La comunicación sería el sexto ámbito esencial de la existencia social, dada su importancia en la sociedad global. Seminario dictado por Aníbal Quijano: Poder y colonialidad del poder, Cátedra América Latina y la Colonialidad del Poder, Universidad Ricardo Palma, Lima, junio de 2010. 
5) Las relaciones con las otras especies y el resto de universo, supone una visión holística e integradora, una comunidad que incluye además al ser humano, hombre y mujer, a la tierra y al universo.

Ámbitos de la existencia que se encuentran presentes en la historia de la humanidad, cada uno ellos y en conjunto son imprescindibles para la vida social. Los diversos ámbitos interrelacionados generan la totalidad de la existencia social y, a la vez, la existencia social genera los diversos niveles societales. La organización de la existencia social es histórica, resultado de un momento determinado, es una relación de equilibrio relativo en la evolución humana. Cada forma de organización de la sociedad, como puede ser la existencia social moderna, tienen una historicidad que marca sus procesos de formación, desarrollo y caducidad sistémica.

La existencia social es una totalidad compleja y, al mismo tiempo, diferenciada por sus ámbitos constitutivos. En efecto, la existencia social es un sistema, resultado de la emergencia de las vinculaciones de los ámbitos entre sí, dispone de una realidad original que va más allá de sus componentes. Sin estos ámbitos integrados no puede haber organización de la sociedad, no hay lugar para el determinismo de alguno de los ámbitos, sólo en conjunto explican la totalidad social. El marxismo y la perspectiva del sistema-mundo enfatizan el ángulo de la economía, los estudios culturales y los estudios postcoloniales subrayan la dimensión simbólica de la sociedad (CASTRO-GÓMEZ e GROSFOGUEL, 2007) y cualquiera otra forma de explicación unilateral que acentúe uno de los ámbitos de manera reduccionista ceden el paso a la fuerza de una interpretación compleja de la naturaleza unitaria de la vida social

Sin embargo, los ámbitos de la existencia social son diversos y tienen orígenes históricamente particulares, lo que le asignan una dinámica relativamente propia. Las cualidades que poseen cada uno de los ámbitos no provienen de alguno de los otros, más bien depende del tejido de relaciones que se establece en conjunto entre ellos, en el caso específico de la subjetividad no se define únicamente por el sexo u otro ámbito de la existencia, es la expresión de todos los ámbitos imbricados en la sociedad. No obstante, las propiedades diferenciadas de los ámbitos, la totalidad social tienen una presencia en cada uno de ellos, el todo se manifiesta en cada componente, lo que los hace parte de la organización de la existencia social. 
El resultado, es que la integración de los ámbitos posibilita la existencia social como una totalidad heterogénea, forma una unidad organizada con sus ámbitos estrucutrales diferenciados. La existencia social es un sistema complejo donde los diferentes ámbitos interactúan mutuamente y se interdefinen de manera conflictiva. La existencia social como totalidad remite a los ámbitos diversos y los ámbitos a la totalidad societal.

En ese contexto, la existencia social es una totalidad que se articulada por el poder, Aníbal Quijano lo denomina patrón histórico de poder. La existencia social se organiza mediante un patrón de poder determinado, que permite delinear la integración de los ámbitos en una unidad societal. No se trata de una composición funcional, donde los diversos ámbitos tienden a la unidad porque se integran de manera complementaria y cohesionada, más bien corresponde a una dinámica compleja de interacción mutua y de conflicto en la sociedad.

La existencia social tiene como característica histórica constitutiva la disputa por el control de las relaciones sociales, de los recursos y de los productos que se generan en cada uno y en el conjunto de los ámbitos de la existencia social: sexo/trabajo/subjetividad/autoridad colectiva/relaciones con las otras especies y el universo. El poder se traza en relaciones de dominación, explotación y conflicto para mantener la organización del sistema y las conductas individuales en la sociedad. Es decir, el poder es dominación, explotación y conflicto entre actores sociales que se disputan el control de la existencia social y se configura según el desarrollo de situaciones históricas específicas (QUIJANO, 2000a:345).

Asimismo, es importante destacar que desde la perspectiva teórica del patrón histórico de poder la relación individuo y sociedad solamente se puede comprender como una unidad complementaria. Las acciones de los individuos interconectados constituyen la existencia social y la existencia social constituye a las acciones individuales. La existencia social es una red de interacciones individuales estructuradas, como el sistema mundo moderno u otro orden social, haciendo que las conductas de los individuos expresen y sean parte de una forma de organización social y, a la vez, esta facilita el desarrollo de las diferencias en los comportamientos individuales.

En ese sentido, la existencia social no puede ser entendida exclusivamente como una entidad externa que trasciende a los individuos, que posee cualidades estructurales más allá de sus miembros y se impone a 
la conducta de los individuos, en la forma como fuera definida por el marxismo y recientemente por Niklas Luhman como un sistema social sin seres humanos. La existencia social tampoco puede ser comprendida únicamente como resultado de la acción creativa individual libre de constreñimientos estructurales, aquí la sociedad se reduce a la agregación de los comportamientos de sus miembros, la vida social aparece como relaciones de sus componentes individuales, según lo desliza el pensamiento posmoderno.

La existencia social como unidad organizada se encuentra en estado de autoproducción permanente a través del tejido interconectado de individuos y se recompone incesantemente a través de las acciones de los individuos. Las acciones de las personas se despliegan en función a específicas estructuras organizacionales a través de conflictos, desordenes y antagonismos por el control de los recursos y productos disponibles, que pueden llevar a mantener el orden sistémico y, al mismo tiempo, pueden distanciarse y socavar el ordenamiento de los propios ámbitos de la existencia social.

Se trata de una relación compleja de acción individual y existencia social. Cuando la reproducción de las acciones individuales de dominación/explotación/conflicto se dirige al mantenimiento y la persistencia de la organización en los ámbitos de existencia social, la sociedad se manifiesta en las acciones de las personas. Para la autoproducción permanente del orden social son imprescindibles las conductas de los individuos que buscan reproducirla. Y, al mismo tiempo, las acciones pueden ser divergentes frente al patrón organizativo, el resultado es que se desarrollan conductas de dominación, explotación y conflicto que tiendan a reconfigurar el control de los recursos y sus productos en cada ámbito de la existencia social. La oposición y modificación social es posible cuando las conductas personales reaccionan y se desvían en relación a un orden social específico.

\section{Elementos para una teoría de la existencia social capitalista.}

La propuesta teórica sobre la existencia social conduce directamente al desarrollo de una teoría más concreta sobre la configuración de la sociedad moderna. En particular, Aníbal Quijano propone una teoría sobre el sistema mundo moderno, colonial y eurocentrado. 
En ese sentido, el patrón histórico de poder moderno, mundial, colonial y eurocentrado se sustenta principalmente en dos dinámicas muy interconectadas. Primero, es un "patrón mundial de poder", un sistema de explotación, dominación y fuente de conflicto de todas las formas de la existencia social ${ }^{5}$ : sexo/trabajo/autoridad/subjetividad/relaciones con las otras especies y el universo, las mismas que se articulan en torno de la hegemonía del capitalismo. Segundo, estas relaciones de poder se estructuran en función de la imposición de la clasificación racial y cultural de las poblaciones. Especificidad que subraya la idea de la raza como el elemento articulador de dominación y jerarquización universal de superioridad/inferioridad entre europeos (junto a las élites blancas) y nativos indios, negros y cholos. Desde hace más de quinientos años, la clasificación "racial" de la población se instituyó desde América Latina como fundamento y en la más profunda forma de dominación del sistema moderno mundial ${ }^{6}$.

La noción de patrón de poder permite definir la sociedad contemporánea a partir del reexamen de la historia de América Latina (QUIJANO, 1988), bajo el influjo de la huella de la obra de Immanuel Wallerstein del sistema mundo y superando las visiones eurocéntricas que establecían que la conquista y América Latina eran una consecuencia directa del desarrollo europeo, se introduce un "giro teórico fundamental" para la comprensión de la modernidad (QUIJANO e WALLERSTEIN, 1992). La modernidad es entendida no como una forma exclusivamente europea sino mundial, que tiene su origen en la conquista de América entre fines del siglo XV y comienzos del siglo XVI. La modernidad es un proceso de constitución simultáneo entre Europa y América Latina, en el que concurren los mismos procesos de conformación del capitalismo. La

\footnotetext{
${ }^{5}$ Véase los trabajos de Aníbal Quijano: "La nueva heterogeneidad estructural de América Latina". En Hueso húmero, $\mathrm{N}^{\circ}$ 26, Lima, 1990, pp. 8-33; Modernidad, identidad y utopía en América Latina. Ediciones Sociedad y Política, Lima, 1988.

${ }^{6}$ Algunos de los más importantes trabajos de Aníbal Quijano: "Colonialidad del poder y clasificación social", ob. cit., "Colonialidad del poder, eurocentrismo y América Latina", en Edgardo Lander (comp.): La colonialidad del saber: eurocentrismo y ciencias sociales. Perspectivas latinoamericanas, CLACSO, Buenos Aires, 2000, pp. 201-246; "Colonialidad del poder, globalización y democracia". Versión revisada. En San Marcos, $\mathrm{N}^{\circ}$ 25, Universidad Nacional Mayor de San Marcos, Lima, 2006. "Raza, Etnia y Nación en Mariátegui: Cuestiones abiertas", en Roland Forgues (Ed.) José Carlos Mariátegui y Europa. La otra cara del descubrimiento. Editorial Amauta, Lima, 1993, pp. págs. 166187.
} 
dependencia latinoamericana representa el lado oscuro de la propia modernidad. Modernidad y colonialismo son aspectos de una misma dinámica mundial. Teoría que permite superar las visiones eurocéntrincas que situaban los comienzos de la modernidad en el siglo XVIII con la exposición del discurso liberal que permitió ejercer una hegemonía de la subjetividad mundial, como lo señalará Foucault, o que se situaba en el siglo XIX cuando occidente se conforma en relación a oriente como lo sugería la perspectiva de los Estudios Poscoloniales (MIGNOLO, 2000)

La existencia social se mundializa como forma inherente del propio desarrollo del capitalismo. Se va configurando un sistema mundo moderno entre los siglos XVI y XVII, que representa un nuevo patrón de poder sin precedente histórico y que sociológicamente tiene un carácter que abarca todo el planeta y a todos sus habitantes por primera vez en la historia universal. Patrón de poder moderno que tiene en el dominio español y portugués del siglo XVI, luego en la supremacía francesa y holandesa del siglo XVIII, continuado por el predominio inglés en el siglo XIX, y con el poderío norteamericano desde el siglo XX como centros hegemónicos mundiales y América Latina como su periferia. En sentido estricto, podemos hablar de una teoría del patrón histórico de poder moderno, mundial, eurocentrado y colonial (QUIJANO, 2000c).

Estas propuestas permitieron plantear uno de los desafíos más grandes para la teoría social de América Latina. Lo excepcional se encuentra en la manera de abordar la modernidad capitalista como expresión de las transformaciones ocurridas en la totalidad del mundo, enfoque que permitió integrar múltiples procesos complejos en una misma realidad global. Visión de la totalidad que permite examinar las tendencias centrales de la estructura de la colonialidad del poder en el mundo actual.

En ese sentido, se establece un patrón de explotación social que integra estructuralmente todas las formas de organización del trabajo. Este patrón de dominación social moderno permite articular esclavitud, reciprocidad, servidumbre, producción mercantil simple y relaciones salariales, desde el siglo XV bajo el predominio del capital. Patrón de poder moderno que reagrupa las diversas formas de organización del trabajo en función de la producción de mercancías para el mercado mundial. El capital impone una lógica por y para el mercado a la diversidad económica y del trabajo en el mundo moderno colonial. De modo particular, en América Latina la organización del trabajo supuso la configuración de formas de producción en una heterogeneidad históricoestructural que implica la coexistencia de sus múltiples modos 
(QUIJANO, 2008d), con lo cual se cuestiona la tesis de la sucesión lineal de modos de producción. La noción de patrón de poder colonial permite reconceptualizar la historia del capitalismo que se concebía como el desarrollo de manera lineal, la cual pasaría por etapas sucesivas. Nunca hubo una historia sucesiva del mundo, siempre han coexistido sociedades y formas de producción, recién con el desarrollo de la modernidad el capital logra una hegemonía sobre la diversidad socioeconómica. Latinoamérica es una totalidad en la que coexisten en el mismo tiempo y espacio maneras de producción y culturas diferentes, y no de sucesión de unas a otras ${ }^{7}$. Es decir, lo que caracteriza América es la simultaneidad y articulación de la comunidad pre-hispánica con formas esclavistas, serviles, mercantiles y del capital, no se trata del desarrollo evolutivo, más bien desde la conquista supuso la imposición en un mismo escenario de un acoplamiento paralelo de todas las formas económicas bajo la hegemonía del capital. Lo específico de América desde el siglo XVI es la integración de sus estructuras de explotación y de dominación en el sistema social moderno y colonial, los trabajadores esclavos, siervos y pequeño productores eran las poblaciones negras, indios y mestizos; mientras que los que detentaban el poder eran los criollos blancos de origen europeo. La raza va a ser el criterio para delimitar las relaciones sociales y económicas en la sociedad contemporánea (QUIJANO, 2008d).

En efecto, el patrón de poder moderno/colonial conllevó a nuevas relaciones intersubjetivas a nivel mundial. El eurocentrismo es el imaginario social, la memoria histórica y la perspectiva de conocimiento que permite organizar todas las subjetividades de los pueblos de la tierra en un gran discurso universal que tienen su centro hegemónico en Europa y Estados Unidos, que se impone colonizando, subordinado e invisibilizando a todas las demás formas de pensamiento (QUIJANO, 2002a). La perspectiva eurocéntica tiene su fundamento en el dualismo radical entre

7 Visión totalizadora de la realidad latinoamericana que Quijano analiza en sus diversos aspectos interrelacionados y definiría el carácter de sus investigaciones, además de los trabajos citados, se destaca "El movimiento campesino peruano y sus líderes", en América Latina, $\mathrm{N}^{\circ}$ 4, Instituto Latinoamericano de Pesquisas Sociais, Rio de Janeiro, 1965; "El proceso de urbanización en América Latina”, en División de asuntos Sociales, CEPAL, Santiago, 1966; "Urbanización y tendencias de cambio rural en América Latina", en División de asuntos Sociales, CEPAL, Santiago, 1967; sobre la naturaleza del imperialismo: Crisis imperialista y clase obrera en América latina , Fondo Editorial popular, Lima, 1974; Imperialismo clases sociales y Estado en el Perú: 1890-1930, Mosca azul, Lima, 1978. 
sujeto-objeto en la producción del conocimiento, que viene desde la ilustración y de las propias bases del paradigma positivista. Separación absoluta que define a la realidad social como aspectos aislados, inmóviles y arrelacionados, dentro de una concepción ahistórica y que no requiere de la idea de totalidad sistémica para su comprensión. En esta visión eurocéntrica, por primera vez el cuerpo es percibido estrictamente como objeto-naturaleza separado radicalmente del sujeto-razón; por lo tanto, se mistifican las categorías y el cuerpo se concibe como raza, un hecho natural, y, de esa forma, algunas razas están más próximas a la naturaleza, como las nativas y negra, y por lo tanto son más primitivas e inferiores, que otras que se acercan más al sujeto-razón, como las europeas, y, por consiguiente, las cuales son más civilizados y superiores (QUIJANO, 1999). La reproducción de la existencia social moderna genera un mismo proceso de dominio de la subjetividad. Este modo de percibir la realidad fue impuesto y admitido como el principio racional del modo dominante de producción del conocimiento desde la conquista de América.

En particular, en América Latina la dependencia históricaestructural ${ }^{8}$ no trata solamente de una forma de dominación por medios exclusivamente coercitivos, también significa una manera de dominación cultural que busca que el imaginario europeo naturalice la dominación, de tal forma que los dominados abandonen su propia cultura, olviden lo que son y dejen de lado su pasado, proyecto de la colonialidad que quiere someter la cultura andina, es decir convertir a los hombres de nuestro continente en hombres hechos a semejanza del occidente.

El patrón de poder moderno colonial y eurocentrado generó el desarrollo de la familia burguesa y la rearticulación del antiguo sistema patriarcal que posibilita establecer el control y disputa del ámbito de las relaciones sexuales, de la reproducción de la especie humana y del placer corporal individual. Las diferencias corporales de sexos entre macho y hembra condicionan diferencias biológicas entre los individuales. Sin embargo, el género es una construcción mental que la modernidad asume sobre las diferencias sociales que sustentan la superioridad jerárquica del hombre, lo masculino y de las relaciones heterosexuales sobre la mujer, lo

8 En particular puede consultarse el texto: "Dominación y cultura (Notas sobre el problema de la participación cultural)", en Dominación y cultura. Lo cholo y el conflicto cultural en el Perú, ob. cit., p. 38. Ensayo publicado originalmente en la Revista Latinoamericana de Ciencias Sociales, $\mathrm{N}^{\circ}$ 1, Santiago de Chile, 1971. También pueden consultarse "El fantasma del desarrollo en América Latina", en Revista Venezolana de Economía y Ciencias Sociales, vol. 6, № 2, Caracas, 2000, p. 85. 
femenino y otras sexualidades. A partir de la conquista de América Latina las relaciones de género se redefinen con la idea central de "raza". En la escala social, al lado de la superioridad del hombre de "raza superior" se añade la dominación de la mujer europea y blanca sobre todos los hombres y mujeres nativos (QUIJANO, 2009c).

Este patrón es moderno, no sólo porque trae el desarrollo de originales formas sociales en la historia humana, sino porque, fundamentalmente, conlleva la producción de ideas inéditas que son parte de un nuevo horizonte de sentido, que acarrea la igualdad social y la libertad individual que van producir la ciudadanía contemporánea, cuya expresión es el Estado-Nación. La autoridad colectiva pública que permite centralizar y enlazar todos los de los ámbitos de existencia social es el Estado-Nación. En América Latina, la expansión del Estado-Nación fue parcial y precaria, la ciudadanía como igualdad jurídico/política de individuos desiguales se bloquea por la persistencia de relaciones de colonialidad que reproducían una desigualdad en base a relaciones étnico/raciales entre los dominadores y las poblaciones nativas del nuevo mundo. Con el desarrollo de la modernidad a partir de la conquista de América Latina se abrió un espacio de demanda y conflicto entre la expansión de las ideas modernas de igualdad y libertad individual con la negación de la ciudadanía a las poblaciones mayoritarias, por su condición "natural" de seres desiguales étnico y racialmente (QUIJANO, 2003).

De la misma manera, la modernidad, colonialidad y eurocentrada al fundamentarse en el dualismo cartesiano destruye la unidad indisoluble de la condición humana, ser a la vez individuos, miembros de la sociedad y parte de una especie del cosmos. El dualismo occidental establece la separación y la hegemonía del hombre en relación a las otras especies, la tierra y el universo, considerados objetos naturales. El influjo productivista y la superioridad humana divinizada en la sociedad capitalista son las formas como se van elaborando los medios de sometimiento y dominio sobre la naturaleza. Situación que ha llevado a poner en peligro la existencia social, las especies y el planeta en su conjunto.

Lo central de la existencia social moderna se fundamenta en la dinámica de la colonialidad étnico-racial, que se convierte en el principio de organización, dominación y clasificación del sistema social.

\section{Crisis del sistema mundo moderno, colonial y global}


Después de 500 años del mundo moderno colonial, asistimos por primera vez a una crisis del sistema en su conjunto. Pareciera que las mutaciones son de orden estructural y afectan todos los niveles de la sociedad, ecológica, económica, política, ética y de la subjetividades. Es decir, todos los elementos del patrón de poder entran en un proceso de desestructuración y adquieren nuevas direccionalidades, cuyas consecuencias no se puede predecir. Momento histórico abierto desde 1973, que produce cambios estructurales en la organización moderna mundial, sólo equivalentes a las grandes modificaciones sociales generadas en los años de la revolución industrial.

En ese sentido, la dinámica de las transformaciones de la globalización, no sólo significan efectos coyunturales del capitalismo, sino más bien implica la reconfiguración del capitalismo moderno global ${ }^{9}$, que se traducen en una profunda declinación de la hegemonía de los EE UU, alteraciones de las bases del sistema productivo, del Estado de bienestar y de la racionalidad del sistema moderno/colonial. Aníbal Quijano denomina a este nuevo periodo histórico de "crisis raigal de la colonialidad global del poder" (QUIJANO, 2011). El sistema capitalista que tuvo su desarrollo inusitado durante los siglos XVI y XVII, su consolidación en los siglos XVIII y gran parte del XX, todo hace pensar que quizás está entrando en una etapa de larga transformación radical desde el año de 1973.

En efecto, la crisis global del sistema se define por su carácter sistémico. Por un lado, se expresa en la crisis del calentamiento global, la explotación desenfrenada del medio ambiente natural que amenaza la propia existencia de la vida misma en el planeta, como resultado directo de la forma de organización de la sociedad moderna desde el siglo XVI (QUIJANO, 2009a). En el Perú la información lo ilustra descarnadamente, se ha perdido irremediablemente el $41 \%$ del hielo de los glaciares de la

9 Henry Bernstein: "A dinâmica de classe do desenvolvimento agrário na era da globalização". En Sociologias, $N^{\circ}$ 27, Universidade Federal do Rio Grande do Sul Brasil, 2011, pp. 53-54. Alain Touraine: Después de la crisis. Por un futuro sin marginación. Paidós, Barcelona, 2011. Agustín Lao-Montes: "Crisis de la civilización occidental capitalista y movimientos antistémicos". En Yuyaykusun, $\mathrm{N}^{\circ} 4$, Universidad Ricardo Palma, Lima, 2011. 
cordillera por el impacto del calentamiento global con todas las implicancias que ello supone ${ }^{10}$.

Por otro lado, el desarrollo del sistema mundo moderno está produciendo una nueva revolución tecnológica que propicia alteraciones sustanciales en la esfera de la producción y de las relaciones del capital con el trabajo. A partir de los años ochenta del siglo pasado la revolución tecnológica empieza a modificar el orden jerárquico panóptico de la sociedad moderna, que dirigía a cada individuo un lugar en las grandes estructuras piramidales de producción. La nueva organización social basada en la automatización implica un cambio decisivo en la sociedad global, reconfigurando las relaciones del capital con el trabajo. Un resultado inmediato, fue una mayor especialización y flexibilización laboral, que trajo consigo la precarización en las condiciones de trabajo, y la otra secuela más mediata y estructural, está suscitando que la relación capital - trabajo pareciera que llega a su término en la forma asalariada, es decir el capitalismo ya no puede reproducir masivamente fuerza de trabajo asalariado, aunque el sistema pueda seguir expandiéndose bajo otras formas: pequeña producción mercantil, relaciones para-esclavistas, servidumbre y hasta formas comunales. Realidad que ahora es fácilmente aceptada y contrastable para los propios países desarrollados ${ }^{11}$. En el caso peruano, este proceso se expresa crudamente en que el $70 \%$ de los trabajadores se encuentra en el sector informal. En otros términos, las bases del capital ya no se encuentran únicamente en la compra y venta de la fuerza del trabajo asalariado y, por consiguiente, el sistema tampoco puede seguir controlando a la población por medio de relaciones asalariadas. El capital global desplaza la dominación hacia el control de la subjetividad y al control de las mentalidades de la población.

${ }^{10}$ El Comercio: Casi la mitad del hielo en los glaciares ha desaparecido, País, 25 de marzo de 2012, Lima, p. a20.

11 Aníbal Quijano: "El Trabajo al final del Siglo XX”, en Ecuador Debate. Revista especializada en Ciencias Sociales, $\mathrm{N}^{\circ}$ 74, Quito, 2008, pp. 187-204. La economía popular y sus caminos en América Latina, Mosca Azul Editores, Lima, 1998, pp. 133144; también puede consultarse "solidaridad' y capitalismo colonial/moderno", en América Latina en Movimiento, $\mathrm{N}^{\circ}$ 430, Quito, 2008, pp. 4-8. Sin embargo, esta propuesta teórica fue formulada originalmente en los años sesenta por Quijano: "Notas sobre el concepto de "marginalidad social", en Imperialismo y marginalidad en América Latina, Mosca Azul, Lima, 1977; originalmente publicado en CEPAL, Santiago, 1966. 
La nueva revolución tecnológica modifica la naturaleza de la crisis del capitalismo. El carácter del capital financiero era coyuntural, aparecía como predominante en cada crisis periódica de la historia del capitalismo, traía concentración del capital, posibilitaba su recuperación y, nuevamente, condicionaba que el capital industrial reasumiera el control de la economía. Sin embargo, después de 1973 la hegemonía del capital financiero se ha convertido en parte inherente del capitalismo global, se ha transformado en la principal forma de generación de beneficios, ahora sólo lo puede hacer mediante la especulación rentista. En los niveles más tecnologizados la producción ya no se puede crear valores nuevos, la fuerza de trabajo se ha ido desplazado de la esfera de la producción, obtener ganancias masivas requiere esencialmente de la realización del capitalismo financiero, que se ha trastocado en parte estructural del sistema moderno global. Como lo ha mostrado el fraude mundial desde el 2008, los estados de Europa y Norteamérica entregaron miles de millones de dólares a las principales empresas financieras, comprometidas directamente en la generación de la crisis económica mundial. En el tercer mundo, las actividades rentistas se ha expotenciado, no solamente porque gran parte de nuestros países han acentuado su carácter de exportadores de materias primas, sino porque los grandes beneficios que obtiene el capital global responden a criterios más rentistas y no productivos. Por ejemplo, para el año 2000 la onza del oro costaba 270 US\$ y el barril del petróleo era de 60 US\$, para inicios del 2012 el oro se sitúa en 1,700 US\$ y el petróleo en alrededor de 108 US\$, con proyecciones hacia el alza continua. Las enormes ganancias del capital global por la explotación de materias primas en el tercer mundo tienen como componente principal la especulación rentista.

En esas condiciones, la actual sociedad moderna ya no puede incluir más a sus miembros como productores asalariados, su incorporación va operar fundamentalmente en términos de consumidores. Los límites del capitalismo global de asimilar a las mayorías como trabajadores asalariados, produce la necesidad de la mercantilización de la subjetividad de las poblaciones mediante el consumismo. Pareciera que el consumismo estaría desplazando las formas racionales de la existencia social por la emoción de la compra y la necesidad por la trivialidad. El viejo capitalismo se sustentaba en la racionalidad weberina, ética ascética que permitió el desarrollo de la acumulación de capital, en el capitalismo global la racionalidad se desliza hacia formas teñidas con la emoción y el impulso del momento. Se trata de convertir a las poblaciones en consumidores, pierden autoridad y entra en crisis las estructuras que orientaban el ideal de trabajo y la racionalidad, ahora con los centros comerciales se expande la 
vida social basada en la ética del consumismo (BAUMAN, 2010). En el Perú, se puede observar que en pocos años estamos asistiendo a la creciente expansión de los centros comerciales, que se vienen conformando en el elemento modular de la vida social. Representan los nuevos espacios sociales de los migrantes andinos asentados en las ciudades y que han venido consolidándose como nuevas clases medias y populares. Pareciera que el consumismo estaría substituyendo la gesta emprendedora productiva y popular de la modernidad sesentera que personificaba esa ola migratoria. En los antiguos barrios y sectores populares, las personas orientaban su consumo según sus necesidades y recursos económicos disponibles, si se quería algo había que esperar, se buscaba tener ahorros y se tenía que trabajar para ello, el consumo se orientaba según las posibilidades reales de los pobladores, predominaba una cierta racionalidad en la vida cotidiana, ahora parece todo lo contrario, se desliza hacia una forma de racionalidad limitada, a la compra emocional. En la sociedad de consumo no son las necesidades las que impulsan las compras, sino, que la compra es un fin en sí mismo, los consumidores necesitan comprar aunque no necesiten lo que compran, por lo general las personas entran sin una idea clara de lo que quieren adquirir e incluso sin querer comprar nada, el deseo de comprar y la decisión a llevarlo a cabo va ser sugerido dentro del propio establecimiento en productos que nunca había pensado ni necesitaban.

Las tendencias de expansión de formas de trabajo no capitalista y de la pequeña producción con la mercantilización de la subjetividad llevan a la reducción de la democracia liberal en la estructura del poder nacional de las sociedades modernas. Este cambio drástico de la preponderancia del liberalismo democrático desde el siglo XIX y de la expansión de las ideas de igualdad y libertad individual, salvo ciertos momentos en los años veinte y treinta, y afianzado después de la Segunda Guerra Mundial. Ahora, con el capitalismo global se produce el deterioro de la hegemonía del liberalismo democrático en el poder nacional de las sociedades metropolitanas y se orientan hacia formas que van, primero, a un liberalismo conservador de la era de Reagan y Bush, expresado en la ideología del neo-conservatismo, más tarde desarrollada, en gran parte en términos culturales, por las propuestas del fundamentalismo conservador y autoritario del Tea Party Movement.

Han contribuido al desarrollo de este proceso de conservadurismo de la democracia y de restricciones de las libertades en los países, la exaltación individualista y egoísta de las personas en una sociedad que sienten que la demarcación sistémica comienza a evaporarse, que se 
combina con la profunda declinación del Estado de bienestar; la creciente expansión de la "fundamentalización" de las ideologías religiosas, como modo de vida de gran parte de la población; y el desarrollo vertiginoso de las llamadas "industrias culturales", donde las imágenes, cine, tv, video, etc., se orientan a la mistificación de la experiencia humana y al desarrollo de formas de legitimación de las ideologías y la violencia represiva (QUIJANO, 2011). Proceso que Boaventura de Sousa denomina la expansión del fascismo social (DE SOUSA SANTOS, 2006).

La crisis de la política nacional en el sistema mundo moderno se encuentra directamente relacionado con el decaimiento de la hegemonía de los Estados Unidos. Aunque, la crisis del poder mundial norteamericano se perfila principalmente en el campo económico, en el terreno militar todavía muestra su enorme poderío global. Desde la década de los setenta, asistimos al declive del papel económico de los Estados Unidos, mientras que incrementaba mundialmente su fuerza militar (QUIJANO, 1987). Paralelamente, se abre un largo periodo transicional de desorden mundial y de surgimiento de un nuevo bloque imperial global (QUIJANO, 2002b) constituido a partir de los estados de los países más desarrollados Norteamerica, Europa y Japón- y del surgimiento de nuevas potencias mundiales -países agrupados en la sigla BRICS que se refiere a Brasil, Rusia, India, China y Sudáfrica-; de la participación de las entidades no estatales del capital financiero transnacional, como el FMI, Banco Mundial y la Organización Mundial del Comercio; y con la presencia gigantesca de las propias corporaciones económicas multinacionales. Esta compleja red de poder global viene reemplazando a la hegemonía norteamericana en el control de la autoridad a nivel mundial. El declive de la hegemonía norteamericana manifiesta la crisis del capitalismo eurocentrado, que desde el siglo XVI representaba la supremacía europea y, luego, de los Estados Unidos hasta los años setenta en el siglo XX.

\section{Los caminos de la des/colonialidad}

La teoría de la existencia social y la teoría de la modernidad, colonialidad y eurocentrada llevan a repensar las posibles alternativas. En primer lugar, una propuesta societal presupone la des/colonialidad de la teoría, que desde sus fundamentos innovadores sobre el patrón de poder y a partir de raíces no eurocéntricas reabran nuevamente el camino de su desarrollo para América Latina y el mundo. Y en segundo lugar, a partir de las prácticas sociales de las poblaciones aventurar nuevas perspectivas que 
permitan imaginar un futuro diferente para la sociedad contemporánea. Dado la originalidad de la teoría de la colonialidad del poder, la construcción de alternativas induce a formular nuevas problemáticas a la realidad contemporánea, que faciliten el debate sobre las vías que puedan remitir a replantear la modernidad y faciliten vislumbrar otro mundo posible.

La perspectiva de la des/colonialidad difiere radicalmente de la propuesta de la descolonización. Para Quijano la des/colonialidad conceptúa la superación del patrón de poder de la modernidad, colonialidad y eurocentrada, que se sustenta en la clasificación étnico/racial de la población mundial y que estructura todos los ámbitos de la reproducción de la existencia social en una unidad socio-histórica mundial. En cambio, la descolonización se refiere al desmantelamiento del control de la autoridad política sobre una estructura de dominación y explotación económica y social por una potencia exterior, situación que puede involucrar a sociedades pre-modernas o contemporáneas. La colonialidad se refiere a las relaciones de poder, a la prolongación contemporánea de las bases que sustentaron la modernidad en América Latina. No obstante, el proceso de descolonización en América latina llevó a que el colonialismo político fuera cancelado, mientras que las relaciones de colonialidad étnico/racistas del poder se prolongan hasta la actualidad (QUIJANO, 2000d).

En efecto, la crítica radical del eurocentrismo pone en tela de juicio al mismo patrón moderno, colonial y global, en particular desde América Latina se desarrolla un proceso de cuestionamiento al constructo de la raza y género que sustentó por más de 500 años la dominación social. La propia crisis del sistema moderno global genera nuevas condiciones sociales que facilitan la emergencia de nuevas formas de resistencia contra la colonialidad global. El resultado, es que desde los noventa se viene estableciendo nuevo patrón global de conflicto que gira en torno a la idea de la raza como fundamento del sistema de poder. El nuevo patrón global de conflicto se estructura, por un lado, a partir de las pugnas en el bloque imperial global entre los Estados Unidos, como potencia hegemónica declinante, y la aparición en el escenario de nuevas potencias mundiales (Brasil, Rusia, India, China y Sudáfrica) y, por otro lado, se define por del desarrollo de los movimientos anti-colonialidad del poder a nivel mundial y de modo particular de América Latina.

Antecedentes del nuevo patrón de conflicto global comenzaron a manifestarse a partir de la Segunda Guerra Mundial, cuando el rechazo 
mundial de la barbarie nazi y del militarismo japonés permitió la deslegitimidad del sistema de poder basado en torno de la raza y la etnicidad. Sin embargo, es desde fines del siglo XX por el desarrollo de los movimientos que cuestionan la idea "raza" como articulador de la dominación moderna y colonial que parecieran que trazan un nuevo momento histórico.

En ese sentido, en los últimos años las poblaciones de todo el mundo, pero partiendo de América Latina han desplegado diversas formas de respuestas a la modernidad global. El desarrollo de los movimientos de la sociedad ha generado la irrupción de un nuevo horizonte de sentido histórico que empieza a revisar la subjetividad eurocéntrica (QUIJANO, 2009b). En particular, los movimientos indígenas latinoamericanos cuestionan la idea de la raza como elemento central de la jerarquización social y, sobre todo, porque están planteando la defensa de las ultimas condiciones de existencia y sobrevivencia del mundo, la floresta, el oxigeno, el agua y la especie humana, al impugnar su privatización, mercantilización y capitalización como aspectos centrales que explicarían el deterioro y la crisis medio ambiental. Por primera vez aparece otro horizonte de sentido histórico, la sociedad toma consciencia de que el capitalismo puede llevar a la desaparición del planeta (LEFF, 2005). En correspondencia, en los últimos años se desarrolla un amplio movimiento de los "indignados" que abarcan los países más desarrollados, la primavera árabe y las revueltas estudiantiles en América Latina, cuyas demandas principales giran en torno el cuestionamiento del desempleo estructural y de las altas tasas de ganancias del capital financiero que condena a la población a vivir en la pobreza, colocando de modo precursor en el discurso de las poblaciones urbanas la aspiración de otro mundo distinto y mejor a la modernidad global. De la misma forma, los movimientos feministas, homosexuales, pacifistas, antiutilitarios, de derechos humanos, antiglobalización y otros desarrollan un conjunto de propuestas idearios, demandas y medidas de lucha que apuntan al reconocimiento de los derechos humanos, de los derechos las mujeres, de los derechos de los homosexuales, de los derechos de la paz, solidaridad, reciprocidad y, en general, a la construcción de una sociedad más justa, ideas que contribuyen a la emergencia de un horizonte de sentido histórico alternativo.

Sin embargo, el surgimiento de un horizonte de sentido histórico no solamente produce una nueva subjetividad sino, lo más importante, es que dicha subjetividad apunta al desarrollo de nuevas prácticas sociales en las poblaciones de América Latina, que de alguna forma se traducen en la 
propuesta del bien vivir, como lo planteara Guaman Poma de Ayala desde los inicios de dominación colonial de América Latina ${ }^{12}$, prácticas que llevan el germen de la des/colonialidad del poder en América Latina.

Buen vivir o bien vivir se refiere a la germinación de prácticas sociales alternativas de la des/colonialidad a la modernidad global por las demandas de los movimientos de nuestro continente. Alternativas que requieren de una alteración total de las desigualdades sociales y del dominio sobre la naturaleza por la colonialidad global y que tienen como fundamento la continuada ampliación y profundización de la democratización de la existencia social. En ese sentido, propuestas que se orientan fundamentalmente ${ }^{13}$, en primer término por la igualdad social de individuos heterogéneos y diversos, como punto de partida de toda la existencia social alternativa, contra la clasificación y jerarquización social, sexual y racial de la población, supone la igualdad frente al acceso de los recursos y bienes y servicios, en ese contexto las agrupaciones y/o identidades serian el resultado de la decisiones libre de gentes libres (QUIJANO, 1992).

Otro elemento esencial, es la reciprocidad entre individuos y grupos socialmente iguales, en la organización del trabajo y la distribución de los productos, frente a la lógica del vivir mejor del bienestar capitalista, del progreso ilimitado, que implica la competencia desenfrenada entre los humanos y que lleva al sometimiento y destrucción de la naturaleza.

\footnotetext{
${ }^{12}$ La obra de Felipe Guaman Poma, de 1615, desarrolla desde el legado andino la primera alternativa de un orden íntegramente diferente a una sociedad colonizada. Como sabemos, su propuesta lo formula en una carta que dirige al Rey Felipe III solicitándole la restauración del orden andino sobre la base de una separación de los indios y de los españoles. Felipe Guaman Poma expone directamente que los conquistadores regresen a España y que dejen a los indios en sus tierras, lo hace desde una concepción mesiánica que separa al rey de España de su dominio político sobre las Indias y lo convierte en una categoría metafísica con la capacidad de restablecer el orden cósmico. Juan Ossio: En busca del orden perdido. La idea de la Historia en Felipe Guaman Poma de Ayala, PUCP, Lima, 2009.

13 Aníbal Quijano: “'Bien vivir' para redistribuir el poder. Los pueblos indígenas y su propuesta alternativa en tiempos de dominación global", en OXFAM: Informe Perú 20092010. Pobreza, desigualdad y desarrollo en el Perú, Lima, 2010, pp. 112-121. "'Solidaridad' y capitalismo colonial/moderno", en América Latina en Movimiento, $\mathrm{N}^{\circ}$ 430, Quito, 2008, p. 7.
} 
El bien vivir supone que todo se encuentra interrelacionado, forma una unidad hombre, comunidad, tierra y universo. El bien vivir apunta al bienestar de toda la comunidad, supone una concepción diferente de la existencia social, una concepción que integra al ser humano y la naturaleza, es la gran comunidad de vida a que incluye además del ser humano, hombre y mujer, a la pachamama (la tierra) y a la energía de la pachakamaq (del universo).

Finalmente, se desarrolla la tendencia a la asociación comunal de la población en escala local, regional o nacional como el modo de producción y gestión directo de la autoridad colectiva, frente a las limitaciones del Estado Plurinacional, que de alguna manera vienen estableciendo en algunos países de América Latina (Bolivia, Ecuador y Venezuela), situación que revela una propuesta más jurídica y declarativa que real, cuyas prácticas siguen delineadas por la colonialidad del poder en las relaciones del Estado y las comunidades nativas, como es el caso de la comunidad Yukpa en Venezuela (LANDER, 2010). Las posibilidades de esta asociación comunal, tienen como reto fundamental encontrar un equilibrio entre lo local y lo global. Pareciera, que esta tendencia a la asociación comunal de la población representa el mecanismo de distribución más eficaz de derechos y entre responsabilidades y recursos y productos en las poblaciones.

En suma, en América Latina y el mundo la des/colonialidad presupone una teoría de la existencia social y una teoría del mundo global. También, la des/colonialidad posibilita la apertura de un debate para comprender la des/colonialidad como una propuesta alternativa a la existencia social. La propuesta de la des/colonialidad hace de la teoría social y de la elaboración de una alternativa societal la fuerza más potente frente a la sociedad moderna/colonial/global y convierte a Aníbal Quijano en su principal figura intelectual.

\section{Resumo}

Este trabalho aborda a des/colonialidade da América Latina e da sociedade contemporânea a partir das proposições do pensador peruano Aníbal Quijano.

Palavras-chave: Des/Colonialidade - América Latina - Aníbal Quijano 
COLONIALITY AND DES/COLONIALITY IN LATIN AMERICA: THEORETICAL ELEMENTS

\section{Abstract}

This article addresses des/coloniality in Latin America and contemporary society through the theoretical proposals of Peruvian thinker Aníbal Quijano.

Keywords: Des/Coloniality - Latin America - Aníbal Quijano

\section{BIBLIOGRAFÍA}

BAUMAN, Zygmunt. (2010). Mundo consumo. Ética del individuo en la aldea global. Barcelona: Paidós.

BERNSTEIN, Henry. (2011). "A dinâmica de classe do desenvolvimento agrário na era da globalização". En Sociologias, n. 27, Universidade Federal do Rio Grande do Sul - Brasil.

CASTRO-GÓMEZ, Santiago y GROSFOGUEL, Ramón. (2007). "Prólogo. Giro decolonial, teoría crítica y pensamiento heterárquico", en El giro decolonial. Reflexiones para una diversidad epistémica más allá del capitalismo global, Bogotá, Siglo del Hombre Editores; Universidad Central, Instituto de Estudios Sociales Contemporáneos y Pontificia Universidad Javeriana, Instituto Pensar.

DE SOUSA SANTOS, Boaventura. (2006). Conocer desde el Sur. Para una cultura política emancipadora. Lima, Fondo Editorial Facultad de Ciencias Sociales UNMSM - Programa de Transformación Global.

El Comercio. (2012). Casi la mitad del hielo en los glaciares ha desaparecido, País, 25 de marzo. Lima.

LANDER, Edgardo. (2010). "Después del levantamiento de la acción del hermano Korta",

CELARG, http://www.elpueblosoberano.net/2010/11/edgardo-lander-celarg-despuesde-el-levantamiento-de-la-accion-del-hermano-korta/ 
LAO-MONTES, Agustín. (2011).“Crisis de la civilización occidental capitalista y movimientos antistémicos". En Yuyaykusun, n. 4, Lima, Universidad Ricardo Palma.

LEFF, Enrique. (2005). "Complejidad, racionalidad ambiental y diálogo de saberes", I Congreso Internacional interdisciplinario de participación, animación e intervención socioeducativa, Barcelona, Centro Nacional de Educación Ambiental.

MEJÍA, Julio. (2009). Sociedad y conocimiento. Los desafíos de la sociología latinoamericana, Lima, Fondo Editorial de la Facultad de Ciencias Sociales, Universidad Nacional Mayor de San Marcos.

MIGNOLO, Walter. (2000). La colonialidad a lo largo y a lo ancho: el hemisferio occidental en el horizonte colonial de la modernidad", en Edgardo Lander (comp.). La colonialidad del saber: eurocentrismo y ciencias sociales. Perspectivas Latinoamericanas, Buenos Aires, CLACSO. ORTÍZZ, Carolina. (2009). "Felipe Guaman Poma de Ayala, Clorinda Matto de Turner, Trinidad Henríquez y la teoría crítica -sus legados a la teoría social contemporánea-“, Yuyaykusun, n. 2, Lima, Departamento de Humanidades, Universidad Ricardo Palma.

OSSIO, Juan. (2009). En busca del orden perdido. La idea de la Historia en Felipe Guaman Poma de Ayala, Lima, PUCP.

QUIJANO, Aníbal. (2011). "Bien vivir: entre el "desarrollo" y la des/colonialidad del poder". En Ecuador Debate, n. 84, Quito.

QUIJANO, Aníbal. (2010a). "'Bien vivir' para redistribuir el poder. Los pueblos indígenas y su propuesta alternativa en tiempos de dominación global", en OXFAM: Informe Perú 2009-2010. Pobreza, desigualdad y desarrollo en el Perú, Lima.

QUIJANO, Aníbal. (2010b). Poder y colonialidad del poder, Lima, Seminario dictado en la Cátedra América Latina y la Colonialidad del Poder, Universidad Ricardo Palma.

QUIJANO, Aníbal. (2009a). "Otro horizonte de sentido histórico", en América Latina en Movimiento, n. 441, Quito.

QUIJANO, Aníbal. (2009b). "Discurso de orden como Doctor Honoris Causa: la crisis del horizonte de sentido colonial/moderno/eurocentrado", 
en Julio Mejía Navarrete (ed.): Sociedad, cultura y cambio en América Latina. I Foro Internacional / Encuentro de la Asociación Latinoamericana de Sociología, Lima, Universidad Ricardo Palma.

QUIJANO, Aníbal. (2009c). "Colonialidad del poder, sexo y sexualidad". Carmen Pimentel (org.): Poder, ciudadanía, derechos humanos y salud mental en el Perú", Lima, CECOSAM.

QUIJANO, Aníbal. (2008a.) "El Trabajo al final del Siglo XX", en Ecuador Debate. Revista especializada en Ciencias Sociales, n. 74, Quito.

QUIJANO, Aníbal. (2008b). “'solidaridad' y capitalismo colonial/moderno", en América Latina en Movimiento, n. 430, Quito.

QUIJANO, Aníbal. (2008c). "Don quijote y los molinos de viento en América Latina" en Ecuador Debate. Revista especializada en Ciencias Sociales, n. 73, Quito.

QUIJANO, Aníbal. (2008d). "Don Quijote y los molinos de viento en América Latina" en Ecuador Debate. Revista especializada en Ciencias Sociales, n. 73, Quito.

QUIJANO, Aníbal. (2006). "Colonialidad del poder, globalización y democracia”. Versión revisada. En San Marcos, № 25, Lima, Universidad Nacional Mayor de San Marcos.

QUIJANO, Aníbal. (2006). "El 'movimiento indígena' y las cuestiones pendientes en América Latina", en Review Fernand Barudel Center, Vol. .XXIX, n. 2, New York.

QUIJANO, Aníbal. (2003). "Notas sobre 'raza' y democracia en los países andinos", en Revista Venezolana de Economía y Ciencias Sociales, vol. 9, $\mathrm{n}^{\circ} 1$, Caracas.

QUIJANO, Aníbal. (2002a). "El Regreso del Futuro y las Cuestiones de Conocimiento", en Catherine Walsh, Freya Schiwy y Santiago CastroGómez (Eds.): Indisciplinar las Ciencias Sociales: Geopolíticas del conocimiento y colonialidad del poder. Perspectivas desde lo andino. Quito, Universidad Andina Simón Bolívar - Ediciones Abya-Yala.

QUIJANO, Aníbal. (2002b). “¿Entre la Guerra Santa y la Cruzada?”. En Economía y Política, IV, $\mathrm{N}^{\circ}$ 9, Universidad de Cuenca, Ecuador. 
QUIJANO, Aníbal. (2001). "Poder y derechos humanos", en Carmen Pimentel (ed.): Poder, salud mental y derechos humanos", Lima, CECOSAM.

QUIJANO, Aníbal. (2000a). "Colonialidad del poder y clasificación social", en Journal of World Systems Research, Volume XI, n. 2, Colorado, USA.

QUIJANO, Aníbal. (2000b). "El fantasma del desarrollo en América Latina", en Revista Venezolana de Economía y Ciencias Sociales, vol. 6, n. 2, Caracas.

QUIJANO, Aníbal. (2000c). "Colonialidad del poder, eurocentrismo y América Latina", en Edgardo Lander (comp.): La colonialidad del saber: eurocentrismo y ciencias sociales. Perspectivas latinoamericanas, Buenos Aires, CLACSO.

QUIJANO, Aníbal. (2000d). "El fantasma del desarrollo en América Latina", en Revista Venezolana de Economía y Ciencias Sociales, vol. 6, $\mathrm{n}^{\circ} 2$, Caracas.

QUIJANO, Aníbal. (1999). "Que tal raza", en: Familia y cambio social, Lima, CECOSAM.

QUIJANO, Aníbal. (1988). "La nueva heterogeneidad estructural de América Latina". En Hueso húmero, $\mathrm{N}^{\circ}$ 26, Lima, 1990, pp. 8-33; Modernidad, identidad y utopía en América Latina. Lima, Ediciones Sociedad y Política.

QUIJANO, Aníbal. (1998.) La economía popular y sus caminos en América Latina, Lima, Mosca Azul Editores.

QUIJANO, Aníbal. (1988). Modernidad, identidad y utopía en América Latina, Lima, Ediciones Sociedad y Política.

QUIJANO, Aníbal. (1993). "Raza, Etnia y Nación en Mariátegui: Cuestiones abiertas", en Roland Forgues (Ed.) José Carlos Mariátegui y Europa. La otra cara del descubrimiento. Lima, Editorial Amauta.

QUIJANO, Aníbal. (1992). "Colonialidad y modernidad/racionalidad". Perú Indígena, vol. 13, n. 29, Lima, Instituto Indigenista. 
QUIJANO, Aníbal. (1987). "Estados Unidos y la crisis centroamericana" (Versión provisoria), Lima.

QUIJANO, Aníbal. (1978). Imperialismo clases sociales y Estado en el Perú: 1890-1930, Lima, Mosca Azul.

QUIJANO, Aníbal. (1974). Crisis imperialista y clase obrera en América Latina, Lima, Fondo Editorial Popular.

QUIJANO, Aníbal. (1971). "Dominación y cultura (Notas sobre el problema de la participación cultural)", en Dominación y cultura. Lo cholo y el conflicto cultural en el Perú, ob. cit., p. 38. Ensayo publicado originalmente en la Revista Latinoamericana de Ciencias Sociales, $\mathrm{N}^{\circ} 1$, Santiago de Chile.

QUIJANO, Aníbal. (1967). "Urbanización y tendencias de cambio rural en América Latina”, en División de asuntos Sociales, Santiago, CEPAL.

QUIJANO, Aníbal. (1966). "Notas sobre el concepto de "marginalidad social", en Imperialismo y marginalidad en América Latina, Lima, Mosca Azul, Lima; originalmente publicado en CEPAL, Santiago, 1977.

QUIJANO, Aníbal. (1966). "El proceso de urbanización en América Latina", en División de asuntos Sociales, Santiago, CEPAL.

QUIJANO, Aníbal. (1965). "El movimiento campesino peruano y sus líderes", en América Latina, $\mathrm{N}^{\circ}$ 4, Rio de Janeiro, Instituto Latinoamericano de Pesquisas Sociais.

QUIJANO, Aníbal y WALLERSTEIN, I. (1992). "Americanity as a Concept. Or the Americas in de Modern World-System", en International Journal of Social Sciences, n. 134, Paris.

TOURAINE, Alain. (2011). Después de la crisis. Por un futuro sin marginación. Barcelona, Paidós.

Data de submissão: 30/01/2014

Data de aprovação: 30/03/2014 